\title{
The Past, Present, and Future of Reading Diagnosis and Remediation
}

\author{
Evan Ortlieb \\ Texas A\&M University - Corpus Christi/Curriculum \& Instruction, Corpus Christi, Texas, USA \\ Email: evan.ortlieb@tamucc.edu
}

\begin{abstract}
Reading remediation has dramatically changed since its beginnings approximately 100 years ago. Research into causation of reading difficulties has progressed from cognitive deficit models to learning styles and back to brain functionality. Classroom teachers and teacher educators alike must refine their practices to meet the ever-changing needs of their students. The instructional delivery methods and strategies used today must match the $21^{\text {st }}$ century needs of students in the age of digital literacy. A brief history of the past, present, and future trends of reading diagnosis and remediation is explained.
\end{abstract}

Index Terms - reading, causation, remediation, readers, struggling, digital literacy

\section{HISTORY}

As it approaches 100 years since the term remedial reading was coined (Smith, 2002), it seems appropriate to examine those practices taken towards reading improvement throughout history, what approaches are currently in use today, and what the future may hold for reading diagnosis and remediation. Students began to be labeled as having reading disabilities in 1896 with British ophthalmologist Pringle Morgan's diagnosis of a 14-year-old boy who had not learned to read, but was otherwise intelligent (Harris, 1967). Although limited research occurred prior to the 1900s in various countries, it was not until the 1910s that the use of norm-referenced tests to measure silent and oral reading proficiencies prevailed in the United States. Debates of the importance of silent reading versus oral reading competency began. In addition, the idea that the reading of words and the comprehension of text were two separate entities began to take prominence. Thorndike (1917) explained, "It appears likely that a pupil may read fluently and feel that the series of words are arousing appropriate thoughts without really understanding the paragraph" (p. 331). He furthered:

Reading is a very elaborate procedure, involving a weighing of each of many elements in a sentence, their organization in the proper relations one to another, the selection of certain of their connotations and the rejection of others, and the cooperation of many forces to determine final responses. (p. 323)

Batteries of diagnostic assessments were created to identify students who had reading disabilities and in turn, needed special types of remedial instruction. "When standardized reading tests became readily available about 1915, school systems were then able to measure the reading ability of their students" (Smith, 1965, as cited in Harris, 1980).

In 1925, the $24^{\text {th }}$ Yearbook of the National Society for the Study of Education was published, which contained a highly influential chapter on diagnosis and remedial work. Shortly thereafter, Arthur Gates, an early leader in diagnostic and prescriptive techniques, authored, The Improvement of Reading (1927), concluding that reading problems were a result of not learning fundamental skills or failing to learn them correctly. Within the first 30 years of recognizing students were having difficulties in reading, research efforts led to the creation of assessment, diagnosis, and remediation techniques that schools could utilize to improve their students' reading abilities and comprehension. Large scale remedial programs began to surface within public school systems in the 1930s. Research and development flourished, with some investigators focusing their attention to a machine approach for diagnosis (eye movement cameras) and remediation (reading pacers). Psychotherapy and the study of emotional problems were often included in reading remediation, as psychologists focused their research on causation rather than instruction in what was known as the mental hygiene movement (Cohen, 1983).

In 1938, Luella Cole projected that reading laboratories would be developed to serve as a place where students could be assessed, diagnosed, and given remedial instruction. In the state of New York, unemployed college graduates were briefly trained and assigned to work with small groups of retarded readers in public schools (Harris, 1967). Colleges and universities foresaw mutual benefits stemming from housing reading laboratories, as graduate reading educators studying to become specialists could refine their practices while developing the skills of struggling readers. An expansion of organized reading clinics in the 1940s emanated. Remedial reading programs spread from elementary to secondary schools and in turn, published materials were created especially for remedial use. Public schools employed additional remedial teachers to combat their students' reading difficulties.

The early 1950s marked the popularity of language-experience approaches to reading instruction, which began in the 1930s. Language-experience approaches are based on activities and stories developed from personal experiences of the learner (McCormick, 1988). Students' emotional disturbances were believed to be underlying causes of reading difficulty, as psychotherapy was recommended in many instances. The publication of Rudolph Flesch's Why Johnny 
Can't Read (1955) marked a philosophical change in approaches to reading instruction. Flesch argued that American schools and how they were teaching children to read was the cause for many students' failures in reading development. He urged educators to return to a phonics-based approach to reading, rather than continue with their whole word method of memorizing what words look like.

Physiological disabilities, such as brain damage, were still blamed for a majority of reading difficulties in the 1960s. In response linguistic approaches that included consistency in letter patterns (i.e. "that fat cat sat on the mat") were believed to provide the missing foundational knowledge to struggling readers. Others thought visual-motor problems were causing reading difficulties. Getman (1965) proposed oculo-motor training so students could more proficiently follow moving targets with their eyes. Researchers began studying cognitive development and doing more field-based research in the classroom. Children were given assessments to determine their strongest modality: visual, auditory, etcetera. Word learning practice and comprehension were focal points of instruction.

The Elementary and Secondary School Act of 1965 was passed to assist schools in the acquisition of resources, texts, and instructional materials for students. Of particular attention were problem readers at schools whose incomes were below the national average. Materials based on linguistic principles included those that were programmed as well as predetermined tutoring programs. Meanwhile, scientists conducted laterality studies on the left and right sides of the brain based on the theory that each specialized for different purposes - the left side processes written and spoken language while the right side processes spatial relationships between objects (Springer \& Deutsch, 1989).

Although studies like Guthrie's (1973) investigation of assembly versus system models of reading comprehension ensued, the 1970s marked a shift towards practical applications and instructional improvements. LaBerge and Samuels (1974) coined the term automaticity, as the concept of fluency became a major goal of intensive reading interventions. Remediation was often given in small groups pulled out from regular classrooms in the 1980s. One-to-one instruction given to struggling first grade readers by a specialized teacher to supplement classroom instruction was central to the Marie Clay's Reading Recovery program. It aimed squarely to develop accuracy of print and then return students to their regular classrooms as average achievers as quickly as possible, once the child's reading acquisition improved to the current grade level. Ironically one-to-one instruction was also sometimes provided by paraprofessionals or volunteer tutors who had limited training and were unsupervised at times. Many schools continued implementing these programs through the 1990s, until concerns developed in regard to funding and research-based evaluation.

Concurrently, the whole language movement began in 1976 and gained popularity in the 1980s (Stahl, McKenna, \& Pagnucco, 1994). It stressed children learned to read and write, as they were exposed to a literate environment and as it related to real-world experiences. Focus was placed on meaning and strategy usage rather than phonics-based approaches, which resulted in critics proclaiming that whole language programs undermined the fundamental skills necessary for students to become proficient readers.

With the advent of the Reading Excellence Act (1997), early reading instruction was again based on phonics-based approaches. It was not until the $21^{\text {st }}$ century that reading remediation expanded to include writing and thinking skills. Early intervention was still valued, but problems were recognized with pull-out programs such as the incongruence between remedial and general education teachers, lost instructional time due to transition from general classroom to place of remediation, and a negative connotation of the label "reading disabled." Some students were unfortunately pulled out during regular class's reading instruction.

\section{PRESENT}

The Reading First program of the No Child Left Behind Act increased federal financial support for reading education from $\$ 300$ million to over $\$ 900$ million in 2002, and allocated a total of over $\$ 5$ billion through 2006; however, these funds could only be designated to methods of reading instruction that were scientifically proven (Ortlieb, 2008). As a result: 1) reading education became center stage and nationally recognized as a prerequisite to learning and success in every subject area, and 2) schools receiving Reading First monies selected remediation techniques directly related to the findings of the National Reading Panel's (2000) report, Teaching Children to Read. With an emphasis on higher accountability, data-driven instruction was linked to measureable outcomes based on standards.

The prevention of reading difficulties through early intervention has also been highlighted in Reading First. Early intervention is defined as identifying and providing services to children who are at risk for developing specific reading disabilities (Snow, Burns, \& Griffin, 1998). One of its goals was to provide more early intervention in hopes of greatly reducing the need for remedial programs. Alongside early intervention is the notion of differentiated instruction. Classroom teachers are expected to provide the accommodations and adaptations necessary for all children to reach their potential. Through adopting practices from gifted education like differentiation, ability grouping, and curricular modification, teachers can remediate students in whole-class settings (Renzulli, 1994; Tomlinson, 1995, 1999). Tomlinson (2001) suggests that teachers should be prepared to address the wide diversity of students in schools through flexible grouping, ongoing assessments, and varying expectations/requirements (Baumgartner, Lipowski, \& Rush, 2003; Gallagher, 2004; Lawrence-Brown, 2004).

Although the aim is commendable, its facilitation is not fostered to the extent that it is envisioned. As a result, specialists and supplementary reading instruction are still needed to provide additional instruction that struggling readers need. Yet, fewer reading specialists are found in schools today. Their roles have changed from providing small 
group reading remediation to being reading coaches. Their duties primarily consist of assisting classroom teachers with their reading instruction, individualization, and instruction. University-based reading clinics have become less popular as well, as universities face the reality of economic hardships and time commitments from their directors. Departments struggle to keep reading clinics afloat, even though the community-based demand is as high as ever.

Participants in remediation programs at elementary schools spend less time reading texts during instruction than do nonparticipating peers (Johnston \& Allington, 1984) as schools cannot always schedule remediation sessions during elective time. As a result, classroom teachers who are ultimately held accountable for their students' success are sometimes uneasy having students participate in pull-out programs. Inevitably, all students will have to take the end-ofthe-year standardized tests.

Although it is universally accepted that comprehension is the ultimate goal of reading, fluency development is overwhelmingly popular with schools that utilize tests like Dynamic Indicators of Basic Early Literacy Skills (DIBELS). Several areas of reading can be measured using DIBELS, but those related to the accuracy and speed at which a child can verbalize sounds, letters, and words are heavily utilized. Instructional procedures usually include teacher modeling appropriate reading of texts and using repeated readings. Meanwhile, comprehension instruction has taken a backseat in popularity all the while school systems place uncanny emphasis on standardized tests and annual yearly progress-both offspring from acts of legislation at all levels of government.

There remains a disconnection between teachers' educational practices and the deficits underlying reading problems identified through research, including: writing and thinking skills crucial elements of remedial instruction, visualprocessing, phonological and semantic decoding, short-term memory, contextual use, language deficiency, and metacognitive deficiency. Meanwhile, acts of legislation guide instruction and the financial support that accompanies them have an enormous influence on what is taught and how teachers remediate students' difficulties in reading.

\section{FUTURE}

While refraining from making futuristic predictions of flying cars, reminiscent of The Jetsons animated television sitcom, I will set forth some conjectures of what will be encompassed in reading remediation based on current practices, research, and trends of today.

Inclusionary practices will continue to prosper as special educators and regular educators will combine their skill sets to address the needs of all students. Pull out programs will be kept to a minimum as virtually all resources will be structured for in-class instruction and remediation. Those seeking additional remediation can venture to universitybased reading clinics, which will gain popularity with the transition of the old classroom of pens, pencils, and papers to that of computers, the Internet, and facilitation. These reading clinics will function as digital literacy hubs.

Technology will no longer be integrated into the curriculum if and when applicable; it will be the primary vehicle for how curriculums are presented and learned. Instead of outlawing many lines of communication in the classroom, the advantages of devices like a cellular telephone, texting device, two-way video camera, conferencing equipment, computer, and the Internet will be fully utilized in the futuristic classroom. The teacher's role will also dramatically shift to instructing in small groups, as students are given portions of the lesson through computer-based tutorials. Those who need to see the skill modeled twice can re-watch the video, seek online guidance, or buzz the teacher for individualized assistance. This advancement will better utilize master teachers, as students can watch videos of 'what to do when they get to unknown words' for example. These word attack skills can be learned through powerful video tutorials, rather than having hundreds of thousands of teachers spending countless hours of time repeating these processes every year with sometimes less effective results. A teacher's function is related to consulting and remediating, spending concentrated amounts of time with students who need additional guidance. Fostering small group and individualized instruction will be standard procedure, as students can progress at their own pace with defined requirements of performance.

\section{A. Research}

Reading remediation will advance alongside experimental research. More refined scope and sequences will be created for the remediation of difficulties in reading, and the individualization of instruction will become eased with the advent of preselected programs for types of learners. For instance, students identified as word callers could be put in research-proven programs of remediation. Teachers will select the best option from those available, and have the ability to modify as necessary.

Literacy hubs (reading clinics) will also become enhanced, especially those affiliated with large research universities. Those in rural areas will benefit through tele-tutoring and web-based instruction as satellite Internet connectivity develops to provide the same speed of web access regardless of geography; however, they will struggle to compete with their urban counterparts by continuing to have difficulties related to financial, structural, and professional support. Brain research will further depict causations of many deficits that lead towards reading difficulties/disabilities. Eden and Moats (2002) state, "Functional brain imaging studies of skill acquisition and practice-induced plasticity have paved the way toward a better understanding of the neural mechanisms of normal reading development (Schlaagar et al., 2002) and reading remediation" (Simos, et al., 2002). Similar scanning equipment will allow researchers to further link 
neurological function to specific activities related to reading. The drastic difference is that educational systems will take notice of these newfound findings, and adopt policies related to these discoveries years later.

\section{B. Practice}

Being integrated with real world applications, digital literacies will continue to flourish as the passive acquiring of knowledge will take a backseat to the active construction of information schema. Digital literacies involve locating, organizing, understanding, evaluating, and creating information. However, the act of teaching students to become digitally literate will become increasingly difficult, as the amount of data exposure will be incredible. Independent pursuits of learning will become mandatory for student success. Discriminating between fact and opinion will be paramount, as the line between the two will become vague at times. Normally one can look at the source such as a text, refereed article, and so on, but the electronic medium as a whole will swell, as it becomes not only the primary source for acquiring information but virtually the only one.

Digital classrooms will follow as schools begin to appropriate funding for electronic resources rather than printed materials. The following is an example of a futuristic second grade classroom:

When the electronic equipment fails, using printed handouts with pen and paper will seem archaic. Interactive books on laptops will be sorted by level, interest, genre, and/or skill, so that students will have more appropriately-geared texts from which to read and learn. While students sit at their desks, their laptops are equipped with stereo headphones, a microphone, and voice recognition software. As each student reads aloud a story during their language arts block, the software detects accuracy of word recognition from each student reading aloud the story. The computer program selects appropriate follow-up activities based on whether the student needs practice in word recognition, expression, pacing, or a host of other subareas of reading. Assessments are completely computer-based as well. Once students have read a number of texts, the software adjusts the level of texts from which to select, and even adjust the readability on future pages of a text as needed, so as to scaffold their learning. Some curricular objectives are even completed through using virtual worlds and global communities like Quest Atlantis' Teacherville.

Just as schooling at every level (elementary, middle, high, and college/university) is already available online in its entirety, its popularity will inevitably control a larger minority of the market. Students from around the globe will become more connected through Internet-based classrooms, but remediating the difficulties of readers will take a different course. It will not become more difficult, because of the advancements that will coincide with the digital revolution. Two-way webcams, voice communication technology, and chat applications will become the norm and be embedded within learning modules. Programmed virtual worlds and global communities will allow students to interact with others to solve real-world problems through completing content-based activities. Management systems for online and hybrid learning should become more user friendly and enriched with options that allow seamless transitions through a scope and sequence with expanded programming manufacturer competition. More personalized sessions of web-based tutoring and remediation will be available live and/or by appointment.

Literacy remediation will remain a focus both within and outside the confines of the classroom. Locating reading materials will occur much less frequently at libraries and in turn, the function of libraries will shift dramatically as resources shift from print to online. Digital library resources are already available, but will continue to become enhanced with multimedia and instructional content. Children will be taught how to use technology from the beginnings of their development. This meshing of learning and technology will have a negative outcome on printed materials, as they become dated and neglected archives of information.

Many believe that books are already dead because they are without the means of being updated or revised. This is especially relevant as non-fiction print is becoming ever-more popular in schools because of its integrated content. Richard Charkin (2006), former CEO of MacMillan Publishing, said that people currently spend more time reading on the Internet than reading printed materials. He summarized that books have characteristics that will lead to their cessation, including having a one-way relationship with the reader, too lengthy, expensive to produce, subject to gatekeepers, not searchable, not linkable, have no metadata, and carry no conversation.

University libraries like the one at Cushing University in Massachusetts are getting rid of their books and reference desks to make room for learning centers with e-readers, flat-screen televisions, and a coffee shop (Prescott, 2009). University-based reading laboratories and clinics will also utilize technology in their approaches to literacy advancement. Digital monitoring equipment already allows professors and students to monitor, record, and study their practices for reflection, study, and advancement. It also enables the professor to monitor multiple sessions simultaneously. Global communities will also be used to link others who can assist with remediation assistance.

As research becomes available depicting the positive outcomes of using technology in teacher development and reading remediation, more university-based reading clinics will follow suit. In these settings, teacher candidates and struggling readers will regularly use software, websites, and e-books to remediate reading difficulties. This will allow preservice teachers to learn these new approaches and as they become incorporated into schools as classroom teachers, they can foster change and professional development to their colleagues. These technology enrichments have not been as readily available in the past, as they are in the $21^{\text {st }}$ century. As a result, publishing companies have created numerous reading series available online with subscriptions. With increased focus on digital literacy, more thorough programs will surface for adoption by schools and universities alike. 


\section{CONCLUSION}

Although hosts of technological devices are already in use today, their widespread use will dominate as the predominant means of learning in classrooms. Rather than passively receiving information from a teacher, learning will consist of mastering digital literacies, including the seeking out and integrating of information into one's schema. As a result, the role of a teacher and a student will change drastically. Remediating difficulties in literacy acquisition will change in turn to meet the altering demands of educational progression. Printed texts will be outdated and literacy educators must continue to advance their skill sets in research, technology utilization, and curricular development if they are to provide their students opportunities for success.

\section{REFERENCES}

[1] Baumgartner, T., Lipowski, M. B., \& Rush, C. (2003). Increasing reading achievement of primary and middle school students through differentiated instruction. Unpublished research project: Saint Xavier University.

[2] Charkin, R. (2006). Charkin blog: The official blog of Richard Charkin. Retrieved October 15, 2009, from http://charkinblog.macmillan.com/default.aspx

[3] Cohen, S. (1983). The Mental Hygiene Movement, the development of personality and the school: The medicalization of American Education. History of Education Quarterly, 23, 123-148.

[4] Eden, G. F., \& Moats, L. (2002). The role of neuroscience in the remediation of students with dyslexia. Nature Neuroscience Supplement, 5, 1080-1084.

[5] Flesch, R. (1955). Why Johnny can’t read. New York: Harper and Row.

[6] Gallagher, D. J. (2004). The importance of constructivism and constructivist pedagogy for disability studies in education. Disability Studies Quarterly, 24.2, 1-15.

[7] Gates, A. I. (1927). The improvement of reading: A program of diagnostic and remedial methods. New York: Macmillan.

[8] Getman, G. N. (1965). The visuomotor complex in the acquisition of learning skills. In J. Hellmuth (Ed.), Learning disorders (Vol. 1). Seattle, WA: Special Child Publications, 49-76.

[9] Guthrie, J. T. (1973). Reading comprehension and syntactic responses in good and poor readers. Journal of Educational Psychology, 65, 294-299.

[10] Harris, A. J. (1967). Five decades of remedial reading. Paper presentation at the International Reading Association Annual Conference, Seattle, WA.

[11] Harris, V. B. (1980). The relationships of selected background factors to the degrees of reading disability evidenced by the clients of a university reading laboratory. Unpublished dissertation. Texas Tech University. Retrieved October 8, 2009, from http://etd.lib.ttu.edu/theses/available/etd-03272009 31295002450236/unrestricted/31295002450236.pdf

[12] Johnston, P., \& Allington, R. (1991). Remediation. In R. Barr, M. L. Kamil, P. B. Mosenthal, \& P. D. Pearson (Eds.), Handbook of reading research (Vol. II). Mahwah, NJ: Lawrence Erlbaum Associates, 984-1012.

[13] LaBerge, D., \& Samuels, S. J. (1974). Toward a theory of automatic information processing in reading. Cognitive Psychology, 6, 293-323.

[14] Lawrence-Brown, D. (2004). Differentiated instruction: Inclusive strategies for standards-based learning that benefit the whole class. American Secondary Education, 32.3, 34-62.

[15] McCormick, T. W. (1988). Theories of reading in dialogue: An interdisciplinary study. New York: University Press of America.

[16] National Reading Panel: Report of the Subgroups. (2000). Teaching children to read: An evidence-based assessment of the scientific research literature on reading and its implications for reading instruction. Washington, DC.

[17] Ortlieb, E. T. (2008). Teaching reading in rural and urban elementary schools. Germany: VDM Verlag Dr. Muller.

[18] Prescott, V. (2009, September 21). Are books dead? New Hampshire Public Radio. Retrieved October 15, 2009, from http://www.nhpr.org/node/27033

[19] Reading Excellence Act, H. R. 2614. 105 ${ }^{\text {th }}$ Cong. (1997).

[20] Renzulli, J. S. (1994). Schools for talent development: A practical plan for total school improvement. Mansfield Center, CT: Creative Learning Press.

[21] Schlaggar, B. L., Brown, T. T, Lugar, H. M., Visscher, K. M., Miezin, F. M., \& Petersen, S. E. (2002). Functional neuroanatomical differences between adults and school-age children in the processing of single words. Science, 296, 1476-1479.

[22] Smith, N. B. (1965/2002). American reading instruction (Special ed.). Newark, DE: International Reading Association.

[23] Simos, P. G., Fletcher, J. M., Bergman, E., Breier, J. I., Foorman, B. R., Castillo, E. M., Davis, R. N., Fitzgerald, M., \& Papanicolaou, A. C. (2002). Dyslexia-specific brain activation profile becomes normal following successful remedial training. Neurology, 58, 1203-1213.

[24] Snow, C. E., Burns, M. S., \& Griffin, P. (1998). Preventing reading difficulties in young children. Washington, DC: National Academy Press.

[25] Springer, S. P., \& Deutsch, G. (1989). Left brain, right brain. San Francisco: Freeman.

[26] Stahl, S. A., McKenna, M. C., \& Pagnucco, J. R. (1994). The effect of whole-language instruction: An update and a reappraisal. Educational Psychologist, 29.4, 175-185.

[27] Thorndike, E. L. (1917). Reading as reasoning: A study of mistakes in paragraph reading. Journal of Educational Psychology, 8.6, 323-332.

[28] Tomlinson, C. (1995). How to differentiate instruction in mixed ability classrooms. Alexandria, VA: Association for Supervision and Curriculum Development. ED 386301.

[29] Tomlinson, C. (1999). The differentiated classroom: Responding to the needs of all learners. Alexandria, VA: Association for Supervision and Curriculum Development. ED 429944.

[30] Tomlinson, C. A. (2001). How to differentiate instruction in mixed-ability classrooms ( $2^{\text {nd }}$ ed.). Alexandria, VA: ASCD. 
[31] U.S. Senate, Committee on Labor and Public Welfare. (1965). Elementary and Secondary Act of 1965: Report to Accompany H.R. 2362. 89 Cong., 1 Sess., St. Rept. 146, p. 21.

[32] Whipple, G. M. (1925). Report of the National Committee on Reading (24th yearbook of the National Society for the Study of Education, Part 1). Bloomington, IL: Public School Publishing.

Evan Ortlieb, Ph.D. is an assistant professor in curriculum and instruction at Texas A\&M University- Corpus Christi, Texas, USA. His areas of expertise include reading clinics, struggling readers, and preservice teacher education. 